\title{
ESTUDO DA EXPOSIÇÃO AMBIENTAL AO GLIFOSATO NA ÁREA AGRÍCOLA DA SERRINHA DO MENDANHA
}

\author{
EROS IZIDORO AMARAL* \\ ANA CRISTINA SIMÕES ROSA** \\ PAULA DE NOVAES SARCINELLI***
}

\begin{abstract}
O objetivo deste trabalho foi avaliar o processo de contaminação ambiental por glifosato na área rural da Serrinha do Mendanha, comunidade periurbana, caracterizada pela presença de pequenos produtores agrícolas que utilizam de modo intensivo o herbicida de interesse para a pesquisa. Efetuou-se a avaliação do processo de trabalho dos agricultores locais mediante aplicação de questionário. A partir dos resultados obtidos pode-se afirmar que o glifosato constitui contaminante ambiental na área estudada e que houve grande exposição ao produto em algum momento da sua aplicação sem a devida proteção. Sugerem-se estudos posteriores que avaliem a água, o ar e matrizes biológicas a fim de investigar os efeitos da exposição ao glifosato sobre a saúde dos trabalhadores atuantes na Serrinha do Mendanha. As informações fornecidas pelos próprios agricultores indicaram a exposição do trabalhador ao produto pelas vias dérmica e respiratória. Além disso, a dispersão pelo ar pode atingir as casas, contaminando crianças, mulheres e outros moradores que sequer trabalham na agricultura. Como os trabalhadores não consomem a mesma água usada para a irrigação da lavoura, não se pode afirmar que ocorra exposição ao glifosato por ingestão. Verificou-se também consumo elevado de outros princípios ativos na região, juntamente com o glifosato, cuja interação pode gerar efeito sinérgico desconhecido sobre a saúde humana e ambiental.
\end{abstract}

PALAVRAS-CHAVE: GLIFOSATO; ÁCIDO AMINOMETILFOSFÔNICO; CONTAMINAÇÃO AMBIENTAL; AGRICULTURA FAMILIAR.

* $\quad$ Mestre em Saúde Pública e Meio Ambiente pela Fundação Oswaldo Cruz (FIOCRUZ), Laboratório de Toxicologia, Centro de Estudos da Saúde do Trabalhador e Ecologia Humana, Escola Nacional de Saúde Pública, Ministério da Saúde, Rio de Janeiro, RJ (e-mail: erosamaral@id.uff.br).

** Mestre em Saúde Pública pela FIOCRUZ, Laboratório de Toxicologia, Centro de Estudos da Saúde do Trabalhador e Ecologia Humana, Escola Nacional de Saúde Pública, Ministério da Saúde, Rio de Janeiro, RJ (e-mail: anacris@ensp.fiocruz.br).

*** Doutora em Biologia Celular e Molecular pela FIOCRUZ, Laboratório de Toxicologia, Centro de Estudos da Saúde do Trabalhador e Ecologia Humana, Escola Nacional de Saúde Pública, Ministério da Saúde, Rio de Janeiro, RJ (e-mail: paula@ensp.fiocruz.br). 


\section{INTRODUÇÃo}

O uso de substâncias químicas nas lavouras, visando à produção em larga escala de forma a mobilizar outros setores da economia (indústrias de fertilizantes, agrotóxicos e insumos) iniciou-se na década de 20. O crescimento do segmento ocorreu de fato a partir da década de 40 , com a Segunda Guerra mundial quando muitas substâncias novas foram sintetizadas para fins bélicos. Após o fim do conflito, a agricultura passou a representar novo campo de ação para essas moléculas em razão de sua ação biocida .

O mercado brasileiro de agrotóxicos cresceu cerca de 190 \% nos últimos 10 anos, frente a 93 $\%$ do mercado mundial como um todo. Nesse mesmo período, o Brasil ultrapassou os Estados Unidos da América (EUA) como maior consumidor desses produtos em todo o planeta (CARNEIRO et al., 2012). Entre os princípios ativos mais consumidos encontra-se o glifosato. Desde 1971, quando foi relatado como herbicida, três tipos de glifosato vêm sendo comercializados: glifosato-isopropilamônio, glifosato-sesquisódio (patenteados pela Monsanto), e glifosato-trimesium (patenteado pela ICl, atual Syngenta) (AMARANTE JR et al., 2002). Classificado no Grupo IV, pouco tóxico, o glifosato age nas plantas inibindo a enzima 5-enolpiruvoilxiquimato-3-fosfato sintase (EPSPS) que bloqueia a síntese de aminoácidos aromáticos. O acúmulo de ácido xiquímico e a impossibilidade da planta sintetizar as moléculas de fenilalanina, tirosina e triptofano, essenciais à sua sobrevivência, ocasionam a morte do vegetal (ROBERTS et al., 2002.). No Brasil, a comercialização do glifosato representa algo em torno de $40 \%$ do consumo nacional de agrotóxicos (CARNEIRO et al., 2012).

Por ser altamente hidrossolúvel, o glifosato tem sido apontado como potencial contaminante ambiental e há diversos relatos de sua detecção em águas superficiais (COX, 1998) Entretanto, há poucas descrições sobre a contaminação de lençóis freáticos, possivelmente devido sua propriedade de alta adsorção ao solo, que varia conforme os diferentes teores de íons metálicos presentes (SOUZA et al., 2005). Sua dispersão pelo ar, juntamente à contaminação de corpos hídricos, são potenciais fontes de exposição de seres humanos. A exposição de forma direta envolve aplicadores de agrotóxicos e agricultores e a indireta abrange, por exemplo, as pessoas que se servem das águas contaminadas (SOUZA et al., 2005).

No meio ambiente, o glifosato é rapidamente convertido ao seu principal metabólito (o ácido amino-metil fosfônico - AMPA) que também apresenta baixa toxicidade, mas com persistência maior. O AMPA foi relacionado ao excesso de divisão celular nos rins e bexigas de ratos, além de provocar diminuição de seu peso (SOUZA et al., 2006).

Indica-se o glifosato para uso diretamente na água visando o controle de plantas aquáticas e para o controle de ervas daninhas anuais e perenes (monocotiledôneas ou dicotiledôneas) em diversas culturas, sendo sua aplicação mais comum no plantio de arroz e de soja (AMARANTE JR et al., 2002). Nesse último caso, o produto passou a ser mais utilizado ainda em virtude da aprovação do plantio transgênico no Brasi em outubro de 2003 (VENDRAMINI, 2004). Como age não seletivamente, o glifosato atua sobre qualquer planta. A soja transgênica utilizada nas lavouras brasileiras, a Roundup Ready (RR), foi modificada geneticamente para ser resistente ao herbicida que pode ser usado em larga escala sobre a cultura.

O plantio de soja transgênica, além de favorecer maior consumo de glifosato e de outros agrotóxicos (como, o fenoxiácido 2,4-D na colheita), traz outros tipos de problemas à saúde humana e ao ambiente, bem como graves problemas sociais. Um dos problemas relacionados ao plantio de transgênicos envolve o pouco conhecimento acerca de seus efeitos a longo prazo, tanto sobre o homem como ao meio ambiente. $\mathrm{O}$ uso de organoclorados nas lavouras e seu posterior banimento mostrou que a liberação de inovação tecnológica sem se conhecer a fundo seus problemas pode ser desastrosa (PORTO, 2008).

Porto (2008) afirmou que os riscos dos novos organismos geneticamente modificados (OGM) são ainda uma incógnita e a introdução de novas cargas genéticas no meio ambiente representa grande preocupação. Segundo os defensores dos transgênicos, essa seria uma preocupação 
infundada, já que sempre houve cruzamento genético natural no meio ambiente. Porém, não se trata mais de cruzamento natural (chamado fluxo gênico vertical) que ocorre entre plantas da mesma espécie. O fluxo gênico horizontal envolve a troca de genes entre espécies diferentes que, na maioria dos casos, não ocorre naturalmente pela impossibilidade de reprodução.

Segundo o Greenpeace (2004), o uso em larga escala de glifosato leva à redução da biodiversidade visto que o produto destrói as plantas silvestres. Isso acaba alterando o ecossistema local, já que existem animais que se alimentam dessas plantas. Para Porto (2008), os riscos do plantio de lavouras transgênicas não se resumem à saúde do homem e do meio ambiente, trazendo impacto social devido à expansão do agronegócio. O cultivo da soja comum, seja pelo uso intenso de agrotóxicos ou pelo simples fato da disseminação da monocultura, já representa fator de suma importância no que diz respeito à perda da biodiversidade e à sobrevivência da agricultura familiar (PORTO, 2008).

Conforme Barreto (2008), o modelo de implantação do cultivo de soja no Brasil foi responsável pela manutenção da estrutura agrária dos latifúndios que excluiu os pequenos produtores. A concentração da posse de terras ocasionou a expulsão de muitos pequenos produtores de suas propriedades. Viladesau (2008) afirmou que a expansão da monocultura de soja ocasionaria ainda o aumento do desemprego, da fome, das diferenças sociais e da violência contra campesinos e os movimentos sociais que os representam. Há ainda os problemas ambientais causados pelas monoculturas de modo geral, como a utilização intensiva de irrigação, ocasionando a salinização dos solos, desertificação, erosão, aparecimento de novas pragas, perda de biodiversidade e exploração de forma errada dos recursos naturais, entre outros.

O glifosato é considerado específico para sua função e teoricamente não apresenta riscos para humanos. Assim como ocorre com outros agrotóxicos, a quantidade definida do produto a ser utilizada no campo (0,36 a 2,16 mg/L) muitas vezes não é respeitada (GLUSCZACK et al. 2007), acarretando "excesso" de exposição ao herbicida. Apesar da propalada inofensividade defendida pelos fabricantes, diversos efeitos colaterais à saúde humana vem sendo atribuídos à sua exposição, tais como: desregulação endócrina (WHO, 2008, HOKANSON et al., 2007; DARUICH, ZIRULNIK e GIMENEZ, 2001; RICHARD et al., 2005; OLIVEIRA et al., 2007; BENACHOUR et al., 2007); desregulação do ciclo celular (VAN DEN HEUVEL, 2005; MARC et al., 2002; MARC, MULNERLORILON e BELLÉ, 2004) e dermatites (PENAGOS et al., 2004; WESTER, QUAN e MAIBACH, 1996).

O objetivo deste trabalho foi avaliar a exposição ambiental ao glifosato na área agrícola da Serrinha do Mendanha, município do Rio de Janeiro.

\section{MATERIAL E MÉTODOS}

\section{1 ÁREA DE ESTUDO}

A comunidade agrícola estudada, localizada na Serrinha do Mendanha (Figura 1), pertence ao bairro de Campo Grande, município do Rio de Janeiro, sendo considerada como extensão da Serra do Mendanha. Apesar de apresentar características comuns às comunidades agrícolas, essa área é considerada como periurbana devido à proximidade dos centros urbanos.

O local estudado caracteriza-se pela presença de pequenos produtores agrícolas que cultivam principalmente chuchu, abobrinha, banana, aipim, jiló e quiabo.

Em estudo realizado por Brito, Gomide e Câmara (2006) na Serrinha do Mendanha, o glifosato foi apontado como o agrotóxico mais utilizado (62 \%), seguido pelo Paraquate (46 \%) e pelo organofosforado Triazofós (38\%).

O procedimento inicial, após a aprovação da pesquisa pelo Comitê de Ética e da Fundação Oswaldo Cruz, foi o contato com a Associação de Moradores do local, vinculada ao Sindicato Rural da cidade do Rio de Janeiro. Preparou-se, então, o questionário a ser respondido pelos agricultores, 
visando coletar informações acerca do uso dos agrotóxicos e da exposição aos produtos durante o processo de trabalho.

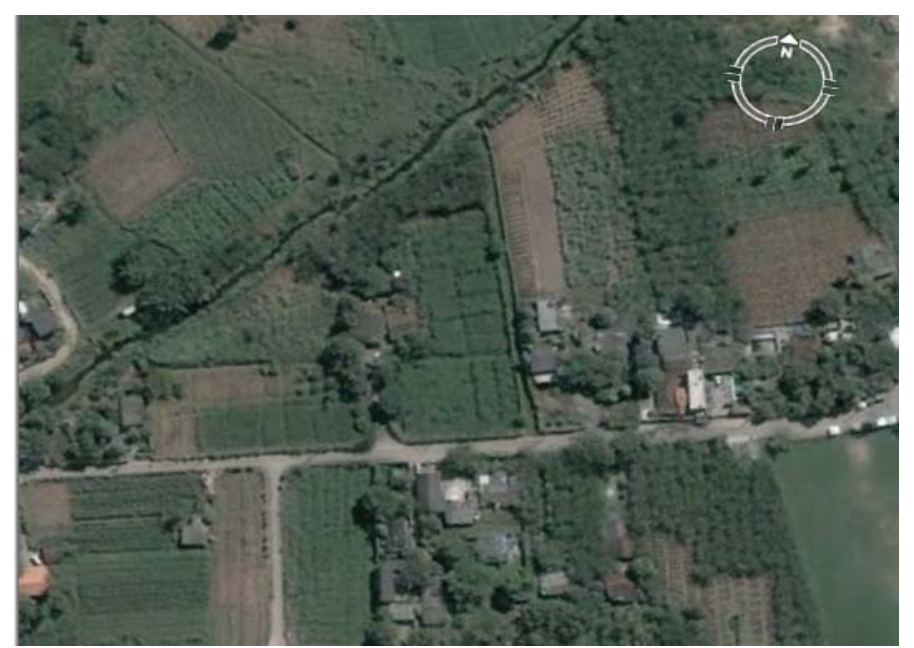

\section{FIGURA 1 - ÁREA AGRÍCOLA DA SERRINHA DO MENDANHA}

Fonte: GOOGLE EARTH, 2009.

\subsection{ANÁLISE ESTATÍSTICA}

Utilizou-se o programa estatístico SPSS, versão 13.0 (IBM BRASIL, 2009) para a análise descritiva das variáveis do questionário.

\section{RESULTADOS E DISCUSSÃO}

\subsection{AVALIAÇÃO DO PROCESSO DE TRABALHO}

Foram entrevistados 11 trabalhadores do sexo masculino em 10 propriedades diferentes, com idade média de 53 anos (mínima e máxima entre 33 e 81 anos). Entre os entrevistados, 9,1 \% se declararam analfabetos; $36,4 \%$ possuem o primário completo; $27,3 \%$ o ginásio incompleto; $18,2 \%$ o primário incompleto e $9,1 \%$ possuem o segundo grau completo. A maioria dos entrevistados (72,7 \%), eram proprietários das terras e $27,3 \%$ empregados.

Os agricultores, em geral, conhecem os equipamentos de proteção individual (EPI), mas não os utilizam por conta do incômodo e da pouca praticidade. A agricultura familiar, praticada no local, gera a exposição pelo uso de agrotóxicos com características diferentes dos grandes produtores. Praticamente todos estão expostos por contato direto (em função do trabalho) ou de outras formas, incluindo situações como o armazenamento inadequado dos produtos e a contaminação da água e alimentos consumidos (GARCIA e ALMEIDA 1991). As mulheres podem ser contaminadas ao ajudar os homens no trabalho agrícola ou ao lavar sua roupa, por exemplo. As crianças podem se contaminar ao brincar perto das lavouras, muito próximas às casas. Pode ocorrer exposição até mesmo dentro de casa, pois os agrotóxicos se dispersam pelo ar e podem adentrar as residências como observado no trabalho de Rosa (2003). Pode-se afirmar que não há distância plausível entre os locais de aplicação e as casas. Além disso, como observaram Brito et al. (2005), a dinâmica dessas comunidades mescla carências diversas como, dificuldade de acesso à educação, ao transporte, ao saneamento básico e aos serviços de saúde de qualidade. Os homens, quase sempre os aplicadores, não recebem qualquer orientação, seguindo apenas as instruções contidas nos rótulos das embalagens. Esse cenário pode fazer com que tais indivíduos e comunidades estejam mais vulneráveis ao risco de adoecimento. 
Brito, Gomide e Câmara (2006) verificaram tendência de mudança de hábito na região, com as mulheres e os jovens trabalhando nas indústrias instaladas no local. Por essa razão, incluiu-se no questionário a pergunta "Você trabalha exclusivamente com a agricultura?". As respostas mostraram que a população busca alternativas para a renda familiar, já que $40 \%$ declararam trabalhar em outras frentes e $27,3 \%$ informaram que seus familiares não trabalham com a agricultura. Quanto ao rendimento familiar, muitos trabalhadores não souberam precisar ou afirmaram variação muito grande de acordo com a época do ano. O maior rendimento admitido foi de cerca de $\mathrm{R} \$ 700,00$.

Buscando comparação do agronegócio com a agricultura familiar incluiu-se pergunta sobre biodiversidade: "Você planta diferentes culturas simultaneamente?". O percentual de respostas sim (100 \%) evidencia a prática da agricultura familiar no local, alternativa agro-ecológica muito menos danosa ao meio-ambiente em relação ao agronegócio.

As respostas das perguntas sobre o uso de agrotóxicos e a percepção acerca desse risco indicaram que $91 \%$ dos agricultores aplicam esses produtos e que $70 \%$ desses não utilizam EPI (considerando EPI completo). Perguntados se tomavam banho após a aplicação de agrotóxicos, 90 \% afirmaram que sim e $10 \%$ apenas lavavam as mãos. Os mesmos $90 \%$ afirmaram lavar as roupas logo após a aplicação e $10 \%$ somente dias depois e junto com outras roupas. Além disso, $30 \%$ declararam lavar suas próprias roupas, 50 \% informaram que as esposas se encarregavam de lavar as roupas e $20 \%$ deixavam tal tarefa para as irmãs.

Os dados obtidos sobre o uso de agrotóxicos na Serrinha do Mendanha constam da Tabela 1 e quando comparados aos do estudo de Brito, Gomide e Câmara (2006), realizado na mesma região, chama a atenção o crescimento do uso do glifosato que saltou de 62 \% em 2006 para 90 \% em 2009.

TABELA 1 - AGROTÓXICOS MAIS UTILIZADOS NA ÁREA AGRÍCOLA DA SERRINHA DO MENDANHA EM 2009

\begin{tabular}{c|c|c|c}
\hline Nome comercial & $\begin{array}{c}\text { Uso } \\
(\%)\end{array}$ & Grupo químico & Classe \\
\hline Roundup (Glifosato) & 90 & Glicina substituída & Herbicida \\
\hline Gramoxone (Paraquate) & 50 & Amônio quaternário & Acaricida \\
\hline Hosthation (Triazofós) & 80 & Organofosforado & Acaricida \\
\hline Tamaron (Metamidofós) & 20 & Organofosforado & Acaricida \\
\hline Folisuper (Parationa metílica) & 20 & Organofosforado & Acaricida \\
\hline Piredan (Permetrina) & 20 & Piretroide & Inseticida \\
\hline
\end{tabular}

Quanto ao armazenamento dos frascos de agrotóxicos, $30 \%$ dos entrevistados afirmaram utilizar local exclusivo para esse fim, $60 \%$ declararam armazená-los junto com outros materiais e $10 \%$ os deixavam na própria lavoura. Quando perguntados sobre o destino das embalagens vazias, $35 \%$ costumam queimá-las, $10 \%$ guardam as embalagens, $15 \%$ as deixam na própria lavoura e $20 \%$ as entregam no local de compra (procedimento correto). Também ocorre o descarte em lixo comum (10\%) ou nos corpos d'água (10 \%). Quanto à origem da água de consumo, $30 \%$ dos entrevistados utilizam fonte natural, $50 \%$ preferem a água fornecida pela Companhia Estadual de Águas e Esgotos do Estado do Rio de Janeiro (CEDAE), $10 \%$ usam água de poço e $10 \%$ optam pela água de poço e da CEDAE. Já para a irrigação, 18,2 \% utilizam água da CEDAE; 27,3\% usam água de poço; $45,5 \%$ preferem a água de rio e 9,0 \% aproveitam a água da chuva (plantação de frutas apenas). 
Mesmo não utilizando EPI, 100 \% dos entrevistados afirmaram acreditar que os agrotóxicos podem causar males à saúde. No entanto, $60 \%$ deles declararam nunca ter sentido qualquer sintoma após a aplicação. Apenas 40 \% sentiram cefaleia, dores no peito, náuseas e vertigens.

\section{CONCLUSÃO}

Conforme os dados obtidos por meio do questionário e da avaliação da exposição, durante o processo de trabalho, pode-se afirmar que o glifosato representa contaminante ambiental na área estudada. As principais vias de exposição do trabalhador ao produto são a dérmica e a respiratória. O fato da água consumida pelos trabalhadores não ser a mesma utilizada na irrigação do plantio diminui o impacto da ingestão como via de exposição. No entanto, a dispersão pelo ar pode atingir as casas, contaminando crianças, mulheres e outros moradores que sequer trabalham na agricultura. Foi verificado também consumo elevado de outros princípios ativos na região, cuja interação pode gerar efeito sinérgico desconhecido sobre a saúde humana e ambiental.

Outros estudos devem ser efetuados para avaliar os níveis de glifosato e AMPA na água do local, incluindo o geoprocessamento da área e plano estratégico de coleta de amostras que leve em conta os fatores determinantes das concentrações nessa matriz. É importante também ampliar as possibilidades de análises do ar e de matrizes biológicas para verificar seus efeitos sobre a saúde dessa população, correlacionando-os com os dados obtidos na avaliação ambiental visando à realização de estudos mais completos e detalhados acerca da saúde dos trabalhadores rurais da Serrinha do Mendanha.

\section{ABSTRACT}

\section{ASSESSMENT OF ENVIRONMENTAL EXPOSURE TO GLYPHOSATE AT THE AGRICULTURAL AREA OF SERRINHA DO MENDANHA (BRAZIL)}

The aim of this study was to assess the environmental contamination by glyphosate in the rural area of "Serrinha do Mendanha" (Brazil), a periurban community. The area is characterized by the presence of small farms in which there is a high consumption of the herbicide studied in the present paper. The work process of local agriculturists was assessed using questionnaire. According to the results it can be stated that glyphosate is an environmental pollutant in the studied area and that there has been a great exposure to the pesticide at any time of its application without proper protection. Further studies evaluating the water, the air and biological matrices are required in order to investigate the effects of the exposure to glyphosate over the health of workers from "Serrinha do Mendanha". Information provided by the workers has indicated dermal and respiratory exposure to the product. Furthermore the dispersion by air can reach the houses contaminating children, women and other residents that do not work in agriculture. Since the workers do not consume the water used to irrigate the crops, it is not possible to state that there is glyphosate exposure by ingestion. It was also observed a wide use of other active principles combined to glyphosate interaction which can generate unknown synergistic effect over human and environmental health.

KEY-WORDS: GLYPHOSATE; AMINOMETHYLPHOSPHONIC ACID; ENVIRONMENTAL CONTAMINATION; FAMILY FARMS.

\section{REFERÊNCIAS}

1 AMARANTE JUNIOR, O.P.; SANTOS, T.C.R.; BRITO, N.M.; RIBEIRO, M.L. Glifosato: propriedades, toxicidade, usos e legislação. Química Nova, v. 25, n. 4, p.589-593, 2002.

2 BARRETO, C.A. Os impactos socioambientais do cultivo de soja no Brasil. Disponível em: http://anppas.org.br/ encontro_anual/encontro2/GT/GT05/clarissa_barreto.pdf Acesso em: 10 out. 2008.

3 BENACHOUR, N.; SIPAHUTAR, H.; MOSLEMI, S.; GASNIER, C.; TRAVERT, C.; SÉRALINI, G.E. Time- and dosedependent effects of Roundup on human embryonic and placental cells. Archives of Environmental Contamination and Toxicology, v.53, p.126-133, 2007. 
4 BRITO, P.F.; GOMIDE, M.; CÂMARA, V. Trabalho e exposição aos agrotóxicos em uma pequena comunidade agrícola no município do Rio de Janeiro. Cadernos de Saúde Coletiva, Rio de Janeiro, v.14, n.3, p. 531-548, 2006.

5 BRITO, P.F.; MELLO, M.G.S.; CÂMARA, V.M.; TURCI, S.R.B. Agricultura familiar e exposição aos agrotóxicos: uma breve reflexão. Cadernos de Saúde Coletiva, Rio de Janeiro, v.13, n.4, p.887-900, 2005.

6 CARNEIRO, F.F.; PIGNATI, W.; RIGOTTO, R.M.; AUGUSTO, L.G.S.; RIZZOLO, A.; FARIA, N.M.X.; ALEXANDRE, V.P.; FRIEDRICH, K.; MELLO, M.S.C. Um alerta sobre os impactos dos agrotóxicos na saúde. Parte 1: Agrotóxicos, segurança alimentar e nutricional e saúde. Rio de Janeiro, RJ: ABRASCO, 2012. (Dossiê ABRASCO).

7 COX, C. Glyphosate (Roundup). J. Pest. Reform., v.18, p.3-17, 1998.

8 DARUICH J.; ZIRULNIK, F.; GIMENEZ, M.S. Effect of the herbicide glyphosate on enzymatic activity in pregnant rats and their fetuses. Environmental Research Section A, v.85, p.226-231, 2001.

9 GARCIA, E.G.; ALMEIDA, W.F. Exposição dos trabalhadores rurais aos agrotóxicos no Brasil. Revista Brasileira de Saúde Ocupacional, v.19, n.72, p.7-11, 1991.

10 GLUSCZAK, L.; MIRON, D.S.; MORAES, B.S.; SIMÕES, R. R.; SCHETINGER, M.R.C.; MORSCH, V.M.; LORO, V. Acute effects of glyphosate herbicide on metabolic and enzymatic parameters of silver catfish (Rhamdia quelen). Comparative Biochemistry and Physiology, Part C, v.146, p.519-524, 2007.

11 GOOGLE EARTH. Área agrícola de Serrinha do Mendanha. Acesso em: 17 de abril de 2009.

12 GREENPEACE. Soja transgênica roundup ready da Monsanto: o que mais pode dar errado?, 2004. Disponível em: http://www.greenpeace.org/raw/content/brasil/documentos/transgenicos/greenpeacebr_040716_transgenicos documento roundup port v1.pdf Acesso em: 10 out. 2008.

13 HOKANSON, R.; FUDGE, R.; CHOWDHARY, R.; BUSBEE, D. Alteration of estrogen-regulated gene expression in human cells induced by the agricultural and horticultural herbicide glyphosate. Human \& Experimental Toxicology, v.26, p.747752, 2007.

14 IBM BRASIL. SPSS Statistic base. V.13.0. São Paulo, 2009.

15 MARC, J.; MULNER-LORILLON, O.; BELLÉ, R. Glyphosate-based pesticides affect cell cycle regulation. Biology of the Cell, v.96, n.3, p.245-249, 2004.

16 MARC, J.; MULNER-LORILLON, O.; DURAND, G.; BELLÉ R. Pesticide Roundup provokes cell division dysfunction at the level of CDK1/cyclin B activation. Chem. Res. Toxicol., v.15, p.326-331, 2002.

17 OLIVEIRA, A.G. et al. Effects of the herbicide Roundup on the epididymal region of drakes Anas platyrhynchos. Reproductive Toxicology, v.23, p.182-191, 2007.

18 PENAGOS, H.; RUEPERT, C.; PARTANEN, T.; WESSELING, C. Pesticide patch test series for the assessment of allergic contact dermatitis among banana plantation workers in Panama. American Contact Dermatitis Society, v.15, n.3, p. 137-145, 2004

19 PORTO, M.F. Riscos, incertezas e vulnerabilidades: transgênicos e os desafios para a ciência e a governança In: SEMINÁRIO INTERNACIONAL DE ESTUDOS INTERDISCIPLINARES, 3., Florianópolis, 2004. Anais... Florianópolis: UFSC, 2004.

20 PROVOOST, J.; REIJNDERS, L.; SWARTJES, F.; BRONDERS, J.; CARLON, C.; D'ALESSANDRO, M.; CORNELIS, C. Parameters causing variation between soil screening values and the effect of harmonization. Science and Policy, v.8, $n$. 5, p.298-311, 2008.

21 RICHARD, S.; MOSLEMI, S.; SIPAHUTAR, H.; BENACHOUR, N.; SÉRALINI, G.E. Differential effects of glyphosate and Roundup on human placental cells and aromatase. Environmental Health Perspectives, v.113, n.6, p.716-720, 2005.

22 ROBERTS, C.W.; ROBERTS, F.; LYONS, R.E.; KIRISITS, M.J.; MUI, E.J.; FINNERTY, J.; JOHNSON, J.J.; FERGUSON, D.J.; COGGINS, J.R.; KRELL, T.; COOMBS, G.H.; MILHOUS, W.K.; KYLE, D.E.; TZIPORI, S.; BARNWELL, J.; DAME, J.B.; CARLTON, J.; MCLEOD, R. The shikimate pathway and its branches in apicomplexan parasites. The Journal of Infectious Diseases, v.185, Suppl. 1, p.S25-36, 2002.

23 ROSA, A.C.S. Avaliação da contaminação no ar por organoclorados na área rural do município de Nova Friburgo. 2003. 77 f. Dissertação (Mestrado em Ciências na área de Saúde Pública), Escola Nacional de Saúde Pública Sérgio Arouca, Rio de Janeiro, RJ, 2003.

24 SOUZA, T.A.; MATTA, M.H.R; MONTAGNER, E.; ABREU, A.B.G. Estudo de recuperação de glifosato e AMPA em solo utilizando-se resinas nacionais. Química Nova, v.29, n.6, p.1372-1376, 2006.

25 SOUZA, T.A.; MATTA, M.H.R. ; MONTAGNER, E.; SOMERA, N.M. Proposta de mecanismo de derivatização do ácido aminometilfosfônico (AMPA) com TFAA e TFE. In: REUNIÃO ANUAL DA SBPC, 57., Fortaleza, 2005. Anais... São Paulo: 
Imprensa Oficial, 2005. v.1. p.106-106.

26 VAN DEN HEUVEL, S. Cell cycle regulation. In: WORMBOOK: the online review of $C$. elegans biology. The $C$. elegans research community, 2005. p.1-16. Disponível em: http://www.wormbook.org/chapters/www_cellcyclereguln/ cellcyclereguln.html Acesso em: 30 set. de 2013.

27 VENDRAMINI, C.R. Origem do Movimento dos Trabalhadores Rurais Sem-Terra. In: CONGRESSO LUSO-AFROBRASILEIRO DE CIÊNCIAS SOCIAIS, 8., Coimbra (Portugal), 2004. Anais... Coimbra: Universidade de Coimbra, 2004.

28 VILADESAU, T.P. El agronegócio de la soja en Paraguay: antecedentes e impactos sociales e econômicos. In: FERNANDES, B.M. Campesinato e agronegócio na América Latina: a questão agrária atual. São Paulo: Ed. Expressão Popular, 2008.

29 WESTER R.C.; QUAN, D.; MAIBACH, H.I. In vitro percutaneous absorption of model compounds glyphosate and malathion from cotton fabric into and through human skin. Food and Chemical Toxicology, v.34, p.731-735, 1996.

30 World Health Organization (WHO). Endocrine disruptors, chapter 2 In: IPCS global assessment of EDCs. Disponível em: http://www.who.int/ipcs/publications/en/ch2.pdf Acesso em: 10 out. 2008. 